\title{
STUDY OF DYNAMIC DRAG OF DISLOCATIONS IN KCI CRYSTALS WITH IMPURITIES AND DIFFERENT DISLOCATION STRUCTURE
}

\author{
O.M. Petchenko, G.O. Petchenko, S.M. Boiko \\ O.M. Beketov National University of Urban Economy in Kharkiv, Kharkiv, Ukraine \\ E-mail: gdaeron@ukr.net
}

The frequency spectra of the dislocation decrement of attenuation $\Delta_{d}(f)$ on $\mathrm{KCl}+\mathrm{Ba}\left(10^{-2}\right.$ wt. $\left.\%\right)$ impurity single crystals with residual deformations $\varepsilon$ of $0.25 ; 0.45 ; 0.75 \%$ at $T=300 \mathrm{~K}$ were investigated by the pulse method in the frequency range $22.5 \ldots 232.5 \mathrm{MHz}$. In the framework of the Granato-Lucke theory, the coefficients of dynamic drag of dislocations $B$ for crystals with different $\varepsilon$ are calculated. It is shown that neither the presence of impurities nor the change of the dislocation structure affects the level of dynamic drag of dislocations.

\section{INTRODUCTION}

This paper continues a series of our works [1-11], in which the influence of various factors - temperature, degree of preliminary deformation and X-ray irradiation on the dynamic and structural characteristics of ionic crystals was studied. One of the most important parameters that play a key role in describing and predicting the process of plastic deformation in solids is the coefficient of dynamic drag of dislocations $B$ [12-14]. As shown in the review [12] in the region of high velocities $\left(v=10^{1} \ldots 10^{3} \mathrm{~m} / \mathrm{s}\right)$, the dislocation, due to its interaction with various elementary excitations of the crystal (electrons, phonons, etc.), significantly loses energy. This is due to the appearance of damping forces acting on the dislocation, the total effect of which is expressed by a coefficient of $B$. It should be noted that the dynamic characteristic $B$ is used not only for the analysis of mechanisms limiting viscous and thermofluctuational motion, but also in cases when the dislocation overcomes obstacles with the help of only mechanical forces taking into account the forces of inertia [12-17].

In order to identify the mechanisms of drag of fastmoving dislocations, both the absolute values of $B$ and the temperature course $B(T)$ on various crystals were previously measured by different experimental methods $[3,9,18-26]$. In addition, the effect of dislocation density in crystals $[4,7,8,18]$ and the degree of X-ray treatment of samples [5-8] on the parameter $B$ was studied.

The main results obtained in these studies are as follows. It turned out that the parameter $B$ depends quite significantly on the crystal temperature. The change in temperature leads to two important processes in the crystals. First, the dislocations change the concentration of point defects - impurities that play the role of pinning centers on dislocations. In acoustic measurements [27], the change with temperature of dislocation resonance characteristics - resonant frequency $f_{m}$ and dislocation decrement of attenuation of ultrasonic waves $\Delta_{m}$ in the maximum as a result of temperature shifts of frequency spectra of dislocation absorption of ultrasound $\Delta_{d}(f)$ was repeatedly recorded. Secondly, when the temperature changes, the mechanisms of mobile dislocations interaction with the viscous medium (the gas of elemen- tary excitations of the crystal) also change. In fact, both of these factors could affect the repeatedly recorded dependence of $B(T)$. The change with the temperature of the concentration of pinning points on the dislocations leads to a change in the parameters of the dislocation resonance, through which $B$ is expressed. As for the change of mechanisms of viscous damping to dislocation motion by the gas of elementary excitations, it is also clear here - in different temperature intervals different mechanisms of dislocation drag appear, which are described by different temperature laws [12, 28-30]. From this point of view, it was very useful to investigate the effect of the presence of stoppers on the dislocations on the parameter $B$.

The Granato-Lucke theory [31], on the basis of which the parameter $B$ is calculated, operates with two types of stoppers - strong (dislocation grid nodes) [32] and weak (point defects) [33]. In papers [4, 7, 8, 18] it was shown that the coefficient of dynamic drag of dislocations in crystals does not depend on either the density of dislocations $\Lambda$ or the dose of X-irradiation $\xi$. That is, it was shown that the concentration of strong stoppers (due to changes in magnitude $\Lambda$ ) and weak stoppers (due to a change in value $\xi$ ) does not affect the level of dynamic damping $B$. This means that the temperature course $B(T)$ is determined exclusively by changes in the mechanisms of dynamic drag of dislocations, the hierarchy of which was established by Alshits [12]. If strong stoppers - this is only one type - dislocation grid, weak stoppers quite a lot (centers of pinning of radiation origin, impurities and magnetically sensitive stoppers). Since the question of centers of radiation origin can be considered closed [8], there are at least two unsolved problems - in relation to impurities and defects of magnetic treatment of crystals.

The main purpose of this work is a precise experimental study of the influence of the impurity structure of the crystal on the absolute value of the coefficient of dynamic inhibition of dislocations $B$ on model $\mathrm{KCl}$ crystals.

The work may be useful for research to increase the radiation resistance of construction materials [34, 35], given that both impurities and fixation centers of radiation origin have a common feature in the string model 
[31] - these are weak stoppers on Friedel-type dislocations.

\section{MATERIALS \\ AND EXPERIMENTAL TECHNIQUES}

In this work the studies of damped dislocation resonance were performed by the pulse method on longitudinal waves in the frequency range $22.5 \ldots 232.5 \mathrm{MHz}$ on impurity single crystals $\mathrm{KCl}+\mathrm{Ba}\left(10^{-2}\right.$ wt.\%) with residual deformations $\varepsilon$ of $0.25 ; 0.45 ; 0.75 \%$ at $T=300 \mathrm{~K}$. The experiments used an original experimental complex [1-9], which provides simultaneous precise measurement of the acousto-mechanical characteristics of crystals by varying the temperature and strain rate using waves of different frequencies. The technology of preparation of samples for research, as well as the technology of measurement were the same as described in [4].

\section{RESULTS AND DISCUSSION}

In Fig. 1 are given the experimental curves of the frequency dependence of the dislocation decrement $\Delta_{d}(f)$ for pre-deformed $\mathrm{KCl}+\mathrm{Ba}\left(10^{-2}\right.$ wt. $\left.\%\right)$ crystals with deformations of $0.25 ; 0.45$, and $0.75 \%$ at $T=300 \mathrm{~K}$. As the deformation in the crystal increases, the existing "growth" dislocations unpinning and new sources appear, such as those that generate long dislocation loops. An increase in the number of such easily mobile dislocations leads to an increase in the maximum decrement $\Delta_{m}$ and reducing the resonant frequency of the maximum $f_{m}$ with deformation (see Fig. 1). This corresponds to the pattern we observed in [4] on relatively pure $\mathrm{KCl}$ crystals. According to [4], only starting from deformations $\varepsilon \sim 0.9 \%$, dislocations appear in other glide planes, which have a fixing effect on the dislocations in the primary plane.

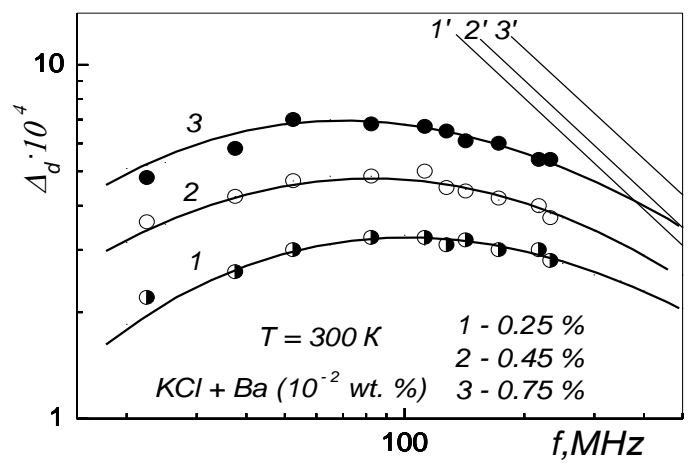

Fig. 1. Frequency dependences of the dislocation decrement $\Delta_{d}(f)$ for pre-deformed $\mathrm{KCl}+\mathrm{Ba}\left(10^{-2} \mathrm{wt} . \%\right)$ crystals at $T=300 \mathrm{~K}$ with deformations $\varepsilon$, \%:

$1-0.25 ; 2-0.45 ; 3-0.75$ and their high-frequency asymptotes 1', 2', 3'

From Fig. 1 it can be seen that the measured dislocation losses depending on the frequency $\Delta_{d}(f)$ have the character of a damped dislocation resonance [31]. It is seen that the measured experimental points are well described by the normalized frequency profile calculated for the case of exponential distribution of dislocation segments by lengths.

Note that when superimposing a theoretical profile on experimental data, according to the recommenda- tions [31], it should be ensured that the binding of the theoretical curve to the experimental data is always conducted exclusively with the focus on experimental points lying on the descending branch of dependence $\Delta_{d}(f)$ and in the resonance area.

Using the measured resonance curves (see Fig. 1) and the data of the previous work [4] in the framework of the Granato-Lucke theory [31] on the relations describing the postresonance and resonance regions of the curves $\Delta_{d}(f)$, the value of the dislocation drag constant $B$ was calculated for samples with pre-deformation values of $0.25 ; 0.45$, and $0.75 \%$.

Fig. 2 shows the results of these calculations, which, for convenience of comparison and clarity, are presented in conjunction with the results of other our works on purer $\mathrm{KCl}$ crystals with a lower content of impurities.

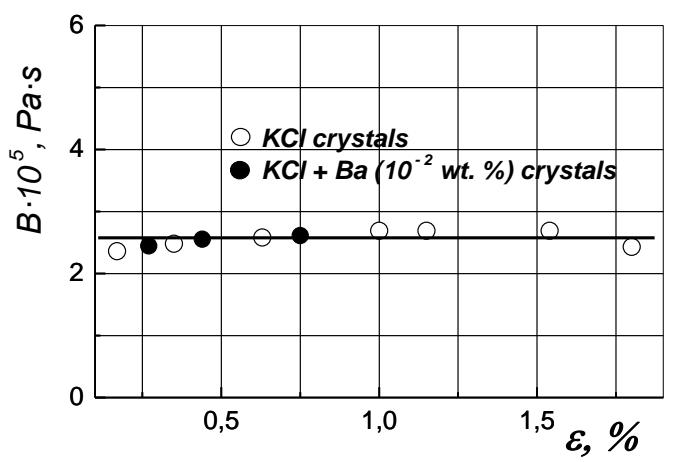

Fig. 2. Dependence of dislocation drag coefficient on the value of pre-deformation of samples in crystals $\mathrm{KCl}+\mathrm{Ba}\left(10^{-2} w \mathrm{t} . \%\right)$ and relatively pure $\mathrm{KCl}$ crystals

It can seen that the experimental data for the $\mathrm{KCl}+\mathrm{Ba}\left(10^{-2}\right.$ wt. $\left.\%\right)$ crystals practically coincide with the data obtained on relatively pure $\mathrm{KCl}$ samples.

Interestingly, both series of data indicate independence from the dislocation structure of parameter $B$ in these crystals. That is, figuratively speaking, Fig. 2 shows the double independence of parameter $B$ in potassium chloride - both from weak stoppers (the presence of impurities), and from the degree of residual crystals deformation - nodes of Frank's dislocation grid.

The experimental data of this work can also be compared with the result of the theoretical calculation performed by the formula [12]

$B=\left[4+\left(\frac{|n|}{G}-6\right)^{2}\right] \frac{\hbar}{b^{3}}\left(\frac{\kappa_{D} b}{2 \pi}\right)^{5}\left[f_{1}\left(\frac{T}{\theta}\right)+\lambda_{\Theta} \frac{\theta}{T} \cdot f_{2}\left(\frac{T}{\theta_{0}}\right)\right]$, where $\hbar=h / 2 \pi$ ( $h$ is Planck's constant); $\kappa_{D}$ is the Debue limit in the phonon spectrum; $n$ is the Murnaghan modulus; $\lambda_{\Theta}=\Delta \cdot f_{1}(1) / 1-\Delta \cdot f_{2}(1)$, where is the phenomenological parameter, that is determined from experiment, $f_{2}(1)=0.92 ; \theta$ is the Debue temperature; $b$ is the Burgers vector modulus. When using the plots of the functions $f_{1}(T / \theta), f_{2}(T / \theta)$ and the values of the quantities $|n| / G=35, \beta=2 \kappa_{D} \cdot r_{0}=30$ (where $r_{0} \approx 3 b$ is the effective radius of the dislocation core), taking from [12], as well as values of parameters found earlier $\Delta=0.5 ; \theta=235.77 \mathrm{~K}$ and $T=300 \mathrm{~K}$, it was obtain absolute value for the damping coefficient $B=0.8 \cdot 10^{-5} \mathrm{~Pa} \cdot \mathrm{s}$ [4]. The obtained theoretical estima- 
tion for $B$ agrees satisfactorily with the average value $B=2.57 \cdot 10^{-5} \mathrm{~Pa} \cdot \mathrm{s}$, found experimentally.

The information obtained is of fundamental importance. At one time there was a heated debate about the fact that the data on parameter $B$, measured on the same crystal by different researchers can not be compared - different sample structure, different crystal growth technologies, processing technologies - different history of sample preparation. The results obtained in this paper suggest that all these differences are completely insignificant. At a fixed temperature in the crystal, neither the presence of impurities nor the variable dislocation density does not lead to a change in the absolute value of $B$.

In paper [25], Alshits suggested that the coefficient of dynamic damping of dislocations $B$ is determined only by the interaction of dislocations with the gas of elementary excitations of the crystal and does not depend on its mechanical state. The results of this work clearly illustrate the validity of this opinion.

\section{CONCLUSIONS}

The frequency spectra of the dislocation decrement of attenuation $\Delta_{d}(f)$ on the impurity crystals $\mathrm{KCl}+\mathrm{Ba}$ $\left(10^{-2}\right.$ wt. $\left.\%\right)$ with residual deformations $0.25 ; 0.45$, and $0.75 \%$ at $T=300 \mathrm{~K}$ was investigated by the pulse method on longitudinal waves in the frequency range 22.5...232.5 MHz. The experimental data were processed in the framework of the Granato-Lucke theory, as a result of which the coefficient of dynamic drag of dislocations $B$ in these crystals was calculated. The results in $B$ were compared with similar data for relatively pure $\mathrm{KCl}$ crystals obtained earlier and with the result of a theoretical calculation of this parameter within the framework of the Alschitz-Indenbom theory. It turned out that the dependence $B(\varepsilon)$ for the crystals $\mathrm{KCl}+\mathrm{Ba}$ $\left(10^{-2}\right.$ wt. \%) is the same both quantitatively and qualitatively as for $\mathrm{KCl}$ crystals. Obtained for the first time double independence of parameter $B$ in potassium chloride - both from weak stoppers (the presence of impurities), and from the degree of residual crystals deformation - nodes of Frank's dislocation grid in conditions of fixed temperature of the experiment is a direct proof that the coefficient of dynamic dislocations drag of crystal is determined only by the interaction of dislocations with the gas of elementary excitations of the crystal and does not depend on its mechanical state.

\section{REFERENCES}

1. A.M. Petchenko, V.I. Mozgovoi, A.F. Sirenko, A.A. Urusovskaya. Return of attenuation and ultrasound speed during stress relaxation in sodium chloride single crystals // FTT. 1989, v. 31, N 6, p. 127-130.

2. A.A. Urusovskaya, A.M. Petchenko, V.I. Mozgovoi. The influence of strain rate on stress relaxation // Phys. Stat. Sol. (a). 1991, v. 125, N 1, p. 155-160.

3. A.M. Petchenko, D.L. Stroilova, A.A. Urusovskaya. Temperature dependence of the coefficient of damping of dislocations in single CsJ crystals // FTT. 1988, v. 30, N 11, p. 3455-3460.

4. O.M. Petchenko, G.O. Petchenko. Phonon drag of dislocations in $\mathrm{KCl}$ crystals with various dislocation structure states // Ukrainian Journal of Physics. 2010, v. 55, N 6, p. 716-721.

5. G.A. Petchenko, A.M. Petchenko. The study of the dislocation resonance in LiF crystals under the influence of the low-dose X-irradiation // Functional Materials. 2010, v. 17, N 4, p. 421-424.

6. G.A. Petchenko. Study of dynamic and structural characteristics in irradiated LiF crystals // Problems of Atomic Science and Technology. 2013, N 2(84), p. $55-59$.

7. G.A. Petchenko. Research of the preliminary deformation and irradiation effect on the viscous damping of dislocation in LiF crystals // Functional Materials. 2013, v. 20, N 3, p. 315-320.

8. G.O. Petchenko, O.M. Petchenko. Research of the elastic wave velocity dispersion in X-ray-irradiated LiF crystals // Ukrainian Journal of Physics. 2013, v. 58, N 10, p. 974-979.

9. A.M. Petchenko, G.A. Petchenko. Features of resonance absorption of longitudinal ultrasound in strained crystals $\mathrm{KBr}$ at temperature variations // Functional Materials. 2007, v. 14, N 4, p. 475-479.

10. G.A. Petchenko, S.S. Ovchinnikov. Effect of the preliminary deformation and irradiation on the optical absorption in LiF crystals // Problems of Atomic Science and Technology. Series "Physics of Radiation Effect and Radiation Materials Science”. 2014, N 2(90), p. 29-33.

11. G.A. Petchenko, A.M. Petchenko. Dependence of electronic color center concentration on the state of irra-diated LiF crystal dislocation structure // Problems of Atomic Science and Technology. Series "Physics of Radiation Effect and Radiation Materials Science". 2015, N 2(96), p. 25-28.

12. V.I. Alshits, V.L. Indenbom. Dynamic drag of dislocations // Usp. Fiz. Nauk. 1975, v. 115, N 3, p. 3-39 (in Russian).

13. V.I. Startsev, V.Ya. Ilyichev, V.V. Pustovalov. Plasticity and strength of metals and alloys at low temperatures. M.: "Metallurgiya", 1975, 328 c.

14. V.S. Postnikov. Inernal friction in metals. M.: "Metallurgiya", 1969, 330 p.

15. S.P. Nikanorov, B.K. Kardashov. Elasticity and Dislocation Inelasticity of Crystals. M.: "Nauka", 1985, $256 \mathrm{p}$.

16. M.A. Krishtal, S.A. Golovin. Internal friction and metal structure. M.: "Metallurgiya",1976, 375 p.

17. A.A. Botaki, A.A. Vorobev, V.A. Ulyanov. Radiation Physics of Ionic Crystals. M.: "Atomizdat", 1980, 208 p.

18. I.V. Gectina, F.F. Lavrentiev, V.I. Startsev. Temperature dependence of the viscous drag coefficient of dislocations in zinc crystals // Physics of Metals and Metallography. 1974, v. 37, N 6, p. 1274-1277.

19. V. Naundorf, K. Lücke. Mechanisms of Internal Friction in Solids. M.: "Nauka", 1976, 91 p.

20. R.M. Stern, A. Granato. Damped dislocation resonance in copper // Internal Friction and Defects in Metals. M.: "Metallurgiya", 1965, p. 149-191.

21. F. Fanti, J. Holder, A.V. Granato. Viscous drag on dislocation in $\mathrm{LiF}$ and $\mathrm{NaCl} / /$ J. Acoust. Soc. Amer. 1969, v. 45, N 6, p. 1356-1366. 
22. A. Hikata, J. Deputat, C. Elbaum. Dislocation interactions with phonons in sodium chloride in the temperature range $77-300 \mathrm{~K} / /$ Phys. Rev. 1972, v. 6, N 10, p. 4008-4013.

23. A. Hicata, B. Chick, C. Elbaum, R. Truell. Dislocation damping in sodium chloride // Appl. Phys. Let. 1963, v. 2, N 1, p. 5-6.

24. A.V. Granato, J. de Clerk, R. Truell. Dispersion of elastic waves in sodium chloride // Phys. Rev. 1957, v. 108, N 3, p. 895-896.

25. N.P. Kobelev, Y.M. Soifer, V.I. Alshits. The relation between viscous and relaxation components of dislocation damping of the high-frequency ultrasound in the copper // FTT. 1979, N 4 (21), p. 1172-1179.

26. O.M.M. Mitchel. Drag of dislocation in LiF // J. Appl. Phys. 1965, v. 36, N 12, p. 2083-2084.

27. R. Truell, Ch. Elbaum, B. Chik. Ultrasound Methods in Solid State Physics. M.: "Mir", 1972, 307 p.

28. V.I. Alshits. "Phonon wind" and dislocation drag // FTT. 1969, v. 11, N 8, p. 2405-2407.

29. V.I. Alshits, Yu.M. Sandler. Flutter mechanism of dislocation drag // Phys. Stat. Sol. (b). 1974, v. 64, N 1, p. 45-49.
30. V.I. Alshits. Raman scattering as a cause of dislocation drag // FTT. 1969, v. 11, N 5, p. 1336-1344.

31. A. Granato, K. Lücke. String model of dislocation and dislocation ultrasound absorption // Physical Acoustic (Part A). M.: "Mir", 1969, v. 4, p. 261-321.

32. N.F. Mott. A theory of workhazdening of metal crystals // Phil. Mag. 1952, v. 43, N 346, p. 1151-1178.

33. J. Fridel. Anomaly in the rigitity modulus of copper allous for small concentration // Phil. Mag. 1953, v. 44, N 351, p. 444-448.

34. V.N. Voyevodin and I.M. Neklyudov. Evolution of the Structural-Phase State and Radiation Resistance of Structural Materials. Kiev: "Naukova dumka", 2006.

35. G.D. Tolstolutskaya, $\quad$ V.V. Ruzhytskyi, V.N. Voyevodin, I.E. Kopanets, S.A. Karpov, A.V. Nikitin. The role of radiation damage on retention and temperature intervals of helium and hydrogen detrapping in structural materials // J. Nucl. Mater. 2013, v. 442 , p. S710-S714.

Статья поступила в редакциию 08.07.2020 г.

\title{
ИЗУЧЕНИЕ ДИНАМИЧЕСКОГО ТОРМОЖЕНИЯ ДИСЛОКАЦИЙ В КРИСТАЛЛАХ КСІ С ПРИМЕСЯМИ И РАЗНОЙ ДИСЛОКАЦИОННОЙ СТРУКТУРОЙ
}

\author{
А.М. Петченко, Г.А. Петченко, С.Н. Бойко
}

Импульсным методом в области частот 22,5...232,5 МГц исследованы частотные спектры дислокационного декремента затухания $\Delta_{d}(f)$ на примесных монокристаллах $\mathrm{KCl}+\mathrm{Ba}\left(10^{-2}\right.$ вес.\%) с величинами остаточных деформаций $(\varepsilon) 0,25 ; 0,45 ; 0,75 \%$ при $T=300$ К. В рамках теории Гранато-Люкке рассчитаны коэффициенты динамического торможения дислокаций $B$ для кристаллов с разными $\varepsilon$. Показано, что ни присутствие примесей, ни изменение дислокационной структуры не влияют на уровень динамического торможения дислокаций.

\section{ВИВЧЕННЯ ДИНАМІЧНОГО ГАЛЬМУВАННЯ ДИСЛОКАЦІЙ В КРИСТАЛАХ КСІ 3 ДОМІШКАМИ І РІЗНОЮ ДИСЛОКАЦЙНОЮ СТРУКТУРОЮ}

\section{О.М. Петченко, Г.О. Петченко, С.М. Бойко}

Імпульсним методом в області частот 22,5...232,5 МГц досліджено частотні спектри дислокаційного декременту згасання $\Delta_{d}(f)$ на домішкових монокристалах $\mathrm{KCl}+\mathrm{Ba}\left(10^{-2}\right.$ ваг.\%) із залишковими деформаціями ( $\varepsilon$ ) 0,$25 ; 0,45 ; 0,75 \%$ при $T=300$ К. У рамках теорії Гранато-Люкке розраховано коефіцієнти динамічного гальмування дислокацій $B$ для кристалів з різними $\varepsilon$. Показано, що ані наявність домішок, ані зміна дислокаційної структури не впливають на рівень динамічного гальмування дислокацій. 